Supporting Information for

\title{
Fluorescent Test Paper via In Situ Growth of COFs for Rapid and Convenient Detection of Pd(II) Ions
}

Yan Lu, ${ }^{\dagger, a}$ Ying Liang, ${ }^{\dagger, a}$ Yuxiang Zhao, ${ }^{\mathrm{a}}$ Meng Xia, ${ }^{\mathrm{a}}$ Xin Liu, ${ }^{\mathrm{a}}$ Tieyin Shen, ${ }^{\mathrm{b}}$ Lijuan Feng, ${ }^{*, b}$ Ning Yuan, ${ }^{*, c}$ and Qi Chen ${ }^{*, a}$

${ }^{a}$ State Key Laboratory of Marine Resource Utilization in South China Sea, Hainan University, Haikou 570228, P. R. China

${ }^{b}$ Department of Bioengineering, Zunyi Medical University (Zhuhai Campus), Zhuhai 519041, China.

${ }^{c}$ School of Chemical and Environmental Engineering, China University of Mining and Technology, Beijing 100083, China

${ }^{\dagger}$ These authors contributed equally to this work.

* Corresponding Authors.

E-mails: chenqi@hainanu.edu.cn (Q. Chen); fljcyczh@126.com (L. Feng); ning.yuan@hotmail.com (N. Yuan) 


\section{S1. Characterization methods and instruments}

Nitrogen adsorption isotherms of XB-COF and XB-Pd-COF were measured with Micromeritics ASAP 2460 automated sorption analyzer, and all samples were degassed at $100{ }^{\circ} \mathrm{C}$ for 10 hours before the test. Powder X-ray diffraction analysis of XB-COF and XB-Pd-COF were performed on Bruker AXS D8 Advance Labx diffractometer at $40 \mathrm{kV}$ and $30 \mathrm{~mA}$ using $\mathrm{Cu} \mathrm{K} \alpha$ radiation over a $2 \theta$ range of $4-40^{\circ}$ at room temperature. $\mathrm{X}$-ray photoelectron spectroscopy analysis of XB-Pd-COF was performed on Kratos AXIS SUPRA electron spectrometer. Fluorescence emission spectroscopy measurements of XB-COF was recorded upon excitation at $380 \mathrm{~nm}$ by Hitachi F-7000 spectrometer. ${ }^{1} \mathrm{H}$ of the monomer was tested on a Bruker DMX400 NMR spectrometer. The FT-IR spectra of materials were recorded by the PerkinElmer FT-IR spectrometer. The morphology of XB-COF and XB-Pd-COF were characterized by field emission scanning electron microscopy (SEM, S-4800, Hitachi, Japan). Transmission electron microscope (TEM) characterization and TEM-EDX mapping were analyzed using a HITACHI HT7700 microscope at an acceleration voltage of $100 \mathrm{kV}$. Before measurement, the samples were completely dispersed in ethanol, and then deposited on porous carbon film on the copper grid.

\section{S2. Synthetic and fluorescence tests}

2,5-Bis(allyloxy)terephthalohydrazide was synthesized by known methods. ${ }^{1,2}$ ${ }^{1} \mathrm{HNMR}\left(500 \mathrm{MHz}, \mathrm{CDCl}_{3}\right) \delta 9.14(\mathrm{t}, J=3.4 \mathrm{~Hz}, 2 \mathrm{H}), 7.86(\mathrm{~s}, 2 \mathrm{H}), 6.07$ (ddt, $J=17.3$, 10.4, 5.1 Hz, 2H), 5.47 (dd, $J=17.3,1.7 \mathrm{~Hz}, 2 \mathrm{H}), 5.37(\mathrm{dd}, J=10.6,1.5 \mathrm{~Hz}, 2 \mathrm{H}), 4.73$ $(\mathrm{d}, J=5.1 \mathrm{~Hz}, 4 \mathrm{H}), 4.17(\mathrm{~d}, J=4.3 \mathrm{~Hz}, 4 \mathrm{H})($ Please see Figure $\mathrm{S} 12)$. 
XB-COF: 2,5 -Bis(allyloxy)terephthalohydrazide $(23 \mathrm{mg}, 0.075 \mathrm{mmol}$ ) and 1,3,5Benzenetricarboxaldehyde $(8.1 \mathrm{mg}, 0.05 \mathrm{mmol})$ were mixed in a $10 \mathrm{~mL}$ Pyrex tube. A mixture of 1,4-dioxane and mesitylene $(2.25 \mathrm{~mL}, 1: 2)$ was added into the tube and sonicated for 10 minutes. The mixture was then added with acetic acid $(100 \mu \mathrm{L}, 6 \mathrm{M})$, flash frozen at $77 \mathrm{~K}$, and degassed under freeze-pump-thaw for three cycles. The tube was sealed and heated at $120^{\circ} \mathrm{C}$ for three days. The solid obtained was exchanged with anhydrous THF ( $5 \mathrm{~mL})$ for 10 times and dried at $100{ }^{\circ} \mathrm{C}$ under vacuum for 8 hours to yield corresponding COFs (the yield of $88 \%$ ). The synthesis method of reference had been slightly modified. ${ }^{3}$

Anion competition tests and $\mathbf{p H}$ stability tests. Stock solutions $(1.0 \mathrm{mM})$ of the $\mathrm{PdCl}_{2}$, $\mathrm{PdBr}_{2}, \mathrm{Pd}\left(\mathrm{NO}_{3}\right)_{2}$, and $\mathrm{Pd}(\mathrm{OAc})_{2}$ were prepared in above methods. Fluorescence spectrum was used to detect the quenching effect of the different $\mathrm{Pd}^{2+}(60 \mu \mathrm{M})$ in the solution of XB-COF $\left(3^{*} 10^{-4} \mathrm{mg} / \mathrm{mL}\right)$. Britton-Robinson buffer solution and water were used to prepare a series of solutions with different $\mathrm{pH}$ values $(\mathrm{pH}=2,4,6,8,10), \mathrm{XB}-\mathrm{COF}$ was dissolved in these solutions and tested its fluorescence spectra after reaction with $\mathrm{Pd}^{2+}$ at $25^{\circ} \mathrm{C}$, respectively. ${ }^{4}$

\section{S3. The relative calculation formula}

The adsorption capacity of $\mathrm{Pd}^{2+}$ was calculated according to the following equation.

$$
q_{\mathrm{e}}=\left(C_{0}-C_{\mathrm{e}}\right) V / m
$$


where $q_{\mathrm{e}}\left(\mathrm{mg} \mathrm{g}^{-1}\right)$ is the sorption amount at equilibrium, $C_{0}\left(\mathrm{mg} \mathrm{L}^{-1}\right)$ and $C_{\mathrm{e}}(\mathrm{mg}$ $\mathrm{L}^{-1}$ ) represent the concentrations of $\mathrm{Pd}^{2+}$ at initial state and sorption equilibrium, respectively; $V(\mathrm{~L})$ and $m(\mathrm{~g})$ are the water volume and the XB-COF weight, respectively.

The pseudo-second-order and pseudo-first-order models were analyzed by the following equations.

$$
\begin{aligned}
& \frac{t}{q_{t}}=\frac{1}{k_{2} q_{\mathrm{e}}{ }^{2}}+\frac{t}{q_{\mathrm{e}}} \\
& \ln \left(q_{\mathrm{e}}-q_{t}\right)=\ln q_{\mathrm{e}}-k_{1} \mathrm{t}
\end{aligned}
$$

where $q_{\mathrm{t}}\left(\mathrm{mg} \mathrm{g}^{-1}\right)$ and $q_{\mathrm{e}}\left(\mathrm{mg} \mathrm{g}^{-1}\right)$ represent the adsorbed $\mathrm{Pd}^{2+}$ amounts of XB-COF at the contact time $\mathrm{t}$ and sorption equilibrium, respectively. $k_{2}\left(\mathrm{~g}(\mathrm{mg} \mathrm{min})^{-1}\right)$ and $k_{1}$ $\left(\min ^{-1}\right)$ represent the corresponding rate constants. ${ }^{5}$ 


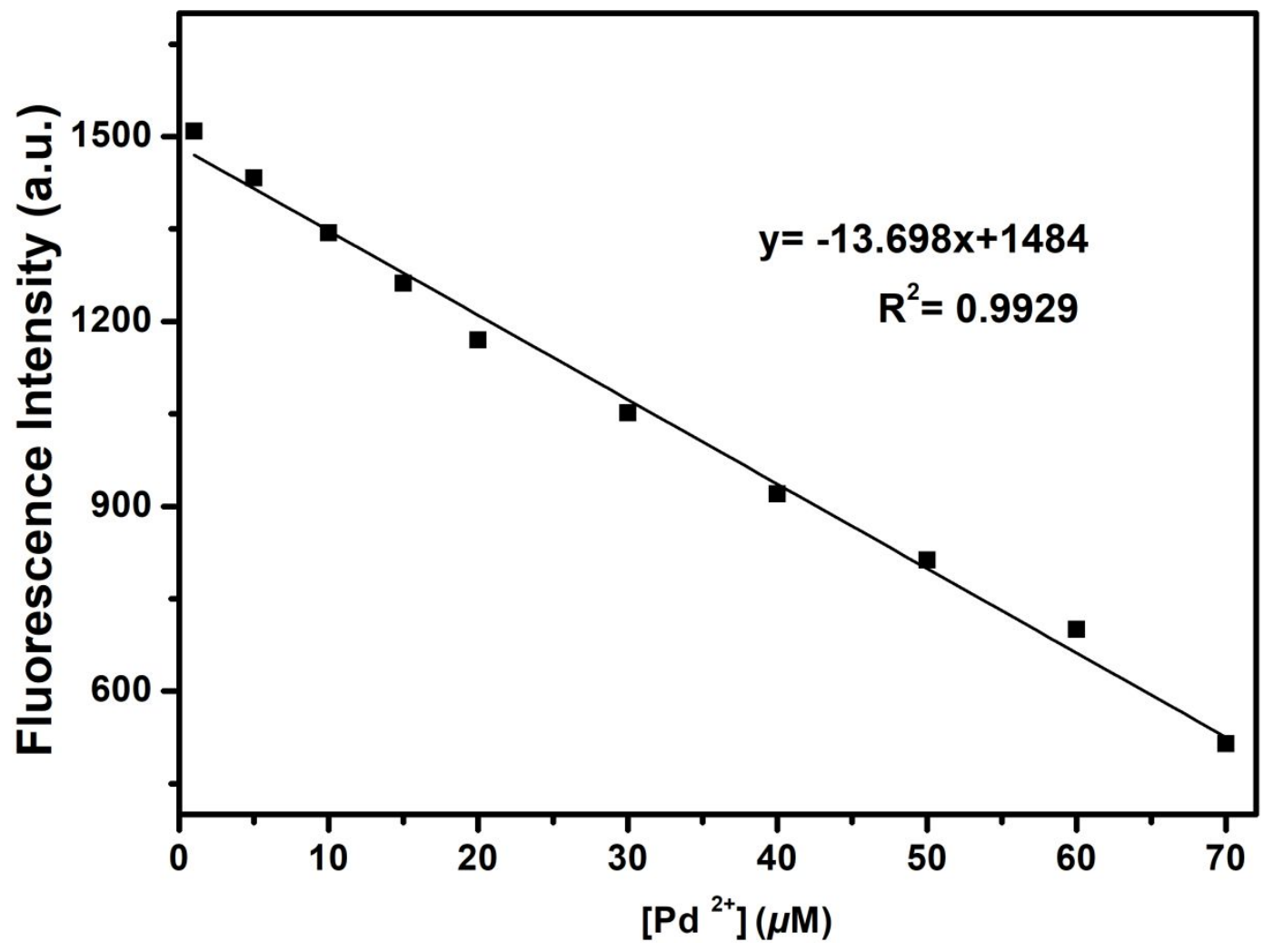

Figure S1. Linear relationship between fluorescence intensity and $\mathrm{Pd}^{2+}$ concentration. The detection limit $=3 \times \sigma / \mathrm{k}=3 \times 1.35 / 13.70 \times 10^{6}=0.29 \mu \mathrm{M}$, where $\mathrm{k}$ represents the slope of the curve equation, and $\sigma$ refers to the standard deviation for the fluorescence intensity of the blank XB-COF suspension. 


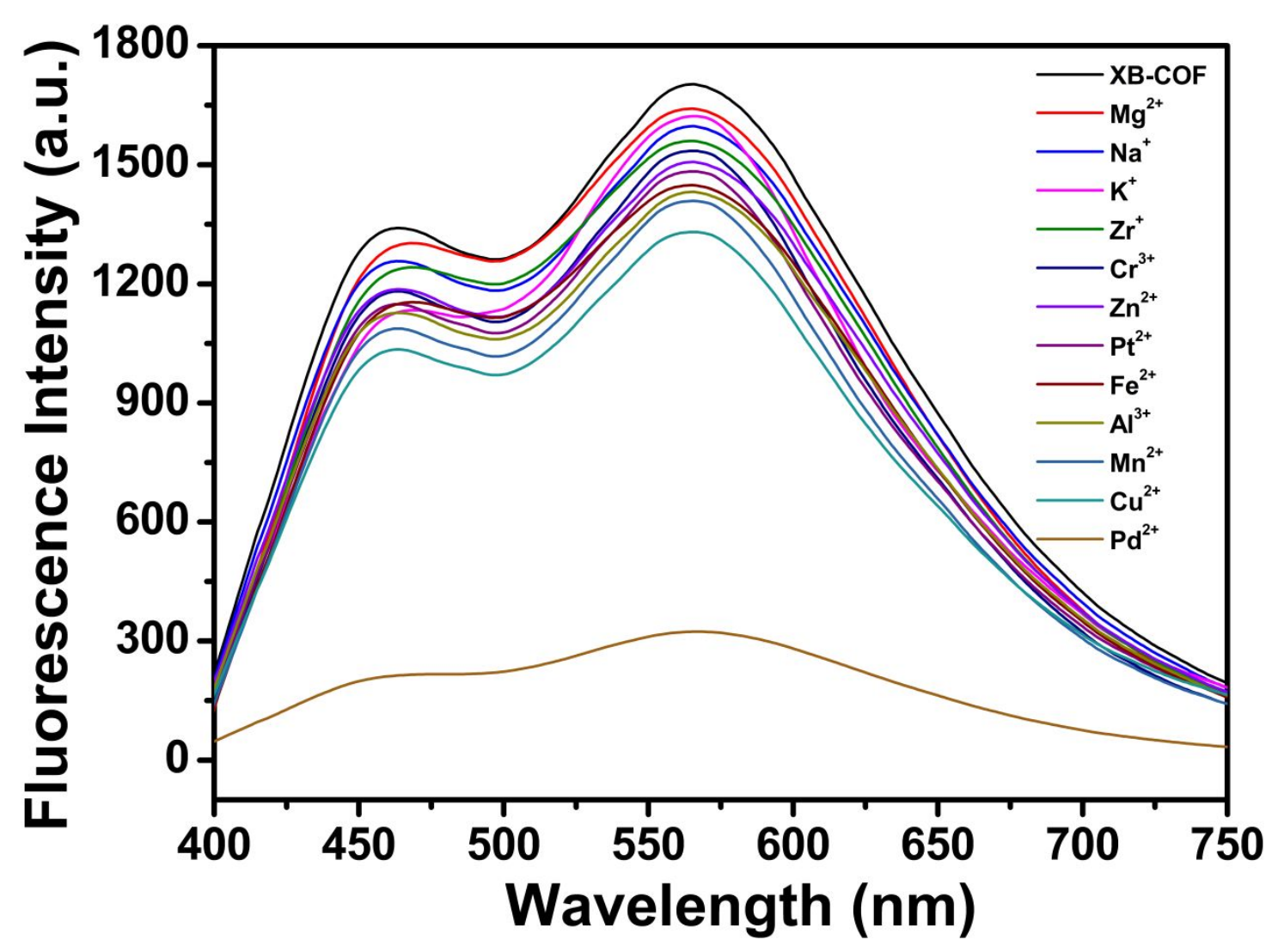

Figure S2. Emission spectra $\left(\lambda_{\mathrm{ex}}=390 \mathrm{~nm}\right)$ of XB-COF in water suspensions containing $60 \mu \mathrm{M}$ of $\mathrm{Mg}^{2+}, \mathrm{Na}^{+}, \mathrm{K}^{+}, \mathrm{Zr}^{2+}, \mathrm{Zn}^{2+}, \mathrm{Pt}^{2+}, \mathrm{Fe}^{2+}, \mathrm{Al}^{3+}, \mathrm{Mn}^{2+}, \mathrm{Cu}^{2+}$, and $\mathrm{Pd}^{2+}$, respectively. 

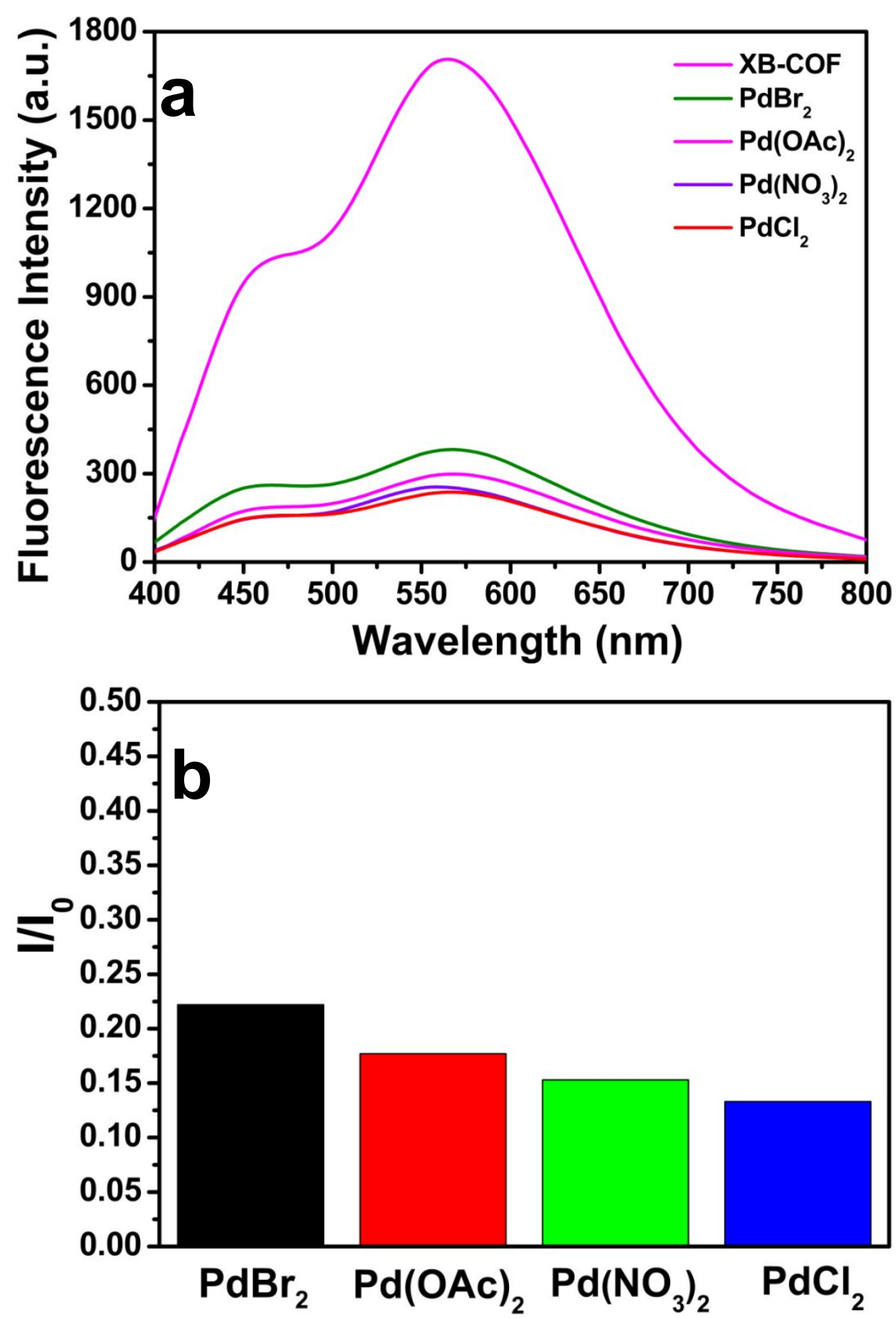

Figure S3. (a) Fluorescence spectra of the XB-COF after adding different divalent palladium salts. (b) $\mathrm{I}_{0}$ represents the fluorescence intensity of $\mathrm{XB}-\mathrm{COF}$, $\mathrm{I}$ is the fluorescence intensity after adding different divalent palladium salts $(60 \mu \mathrm{M})$. 

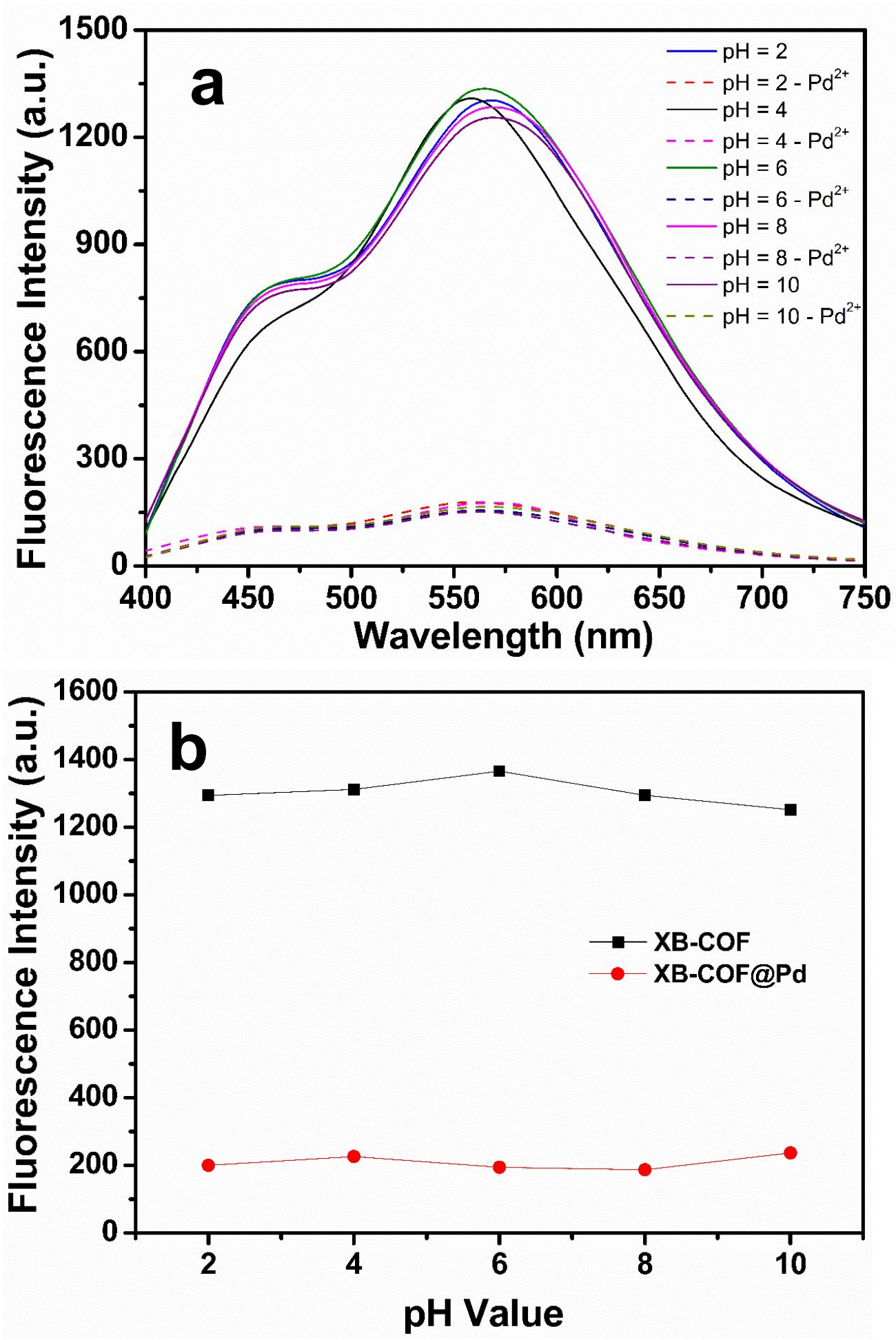

Figure S4. (a) Fluorescence spectra of the $\mathbf{X B}-\mathbf{C O F}$ at different $\mathrm{pH}$ with and without the addition of $\mathrm{Pd}^{2+}(60 \mu \mathrm{M})$. (b) The effect of $\mathrm{pH}$ on the fluorescence intensity of the XB-COF with and without the addition of $\mathrm{Pd}^{2+}$. 
Table S1 Porosity data and adsorbing capacity of COFs

\begin{tabular}{|c|c|c|c|c|c|}
\hline Materials & $\begin{array}{l}\mathrm{S}_{\mathrm{BET}}{ }^{\mathrm{a}} \\
\left(\mathrm{m}^{2} \mathrm{~g}^{-1}\right)\end{array}$ & $\begin{array}{l}\mathrm{S}_{\text {Langmuir }} \mathrm{b} \\
\left(\mathrm{m}^{2} \mathrm{~g}^{-1}\right)\end{array}$ & $\begin{array}{l}\mathrm{V}_{\text {total }}{ }^{\mathrm{c}} \\
\left(\mathrm{m}^{3} \mathrm{~g}^{-1}\right)\end{array}$ & $\begin{array}{l}\mathrm{D}_{\text {pore }}{ }^{\mathrm{d}} \\
(\mathrm{nm})\end{array}$ & $\begin{array}{l}\mathrm{Q}_{\mathrm{e}} \mathrm{e} \\
\left(\mathrm{mg} \mathrm{g}^{-1}\right)\end{array}$ \\
\hline XB-COF & 365 & 330 & 0.27 & 2.35 & 120 \\
\hline XB-Pd-COF & 239 & 214 & 0.19 & 1.88 & 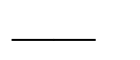 \\
\hline
\end{tabular}

${ }^{a}$ Specific surface area calculated according to BET theory. ${ }^{b}$ Specific surface area calculated by Langmuir theoretical model. ${ }^{c}$ Total pore volume at $P / P_{0}=0.99 .{ }^{d}$ Data calculated with the NLDFT method. ${ }^{\text {e }}$ Maximum adsorption. 


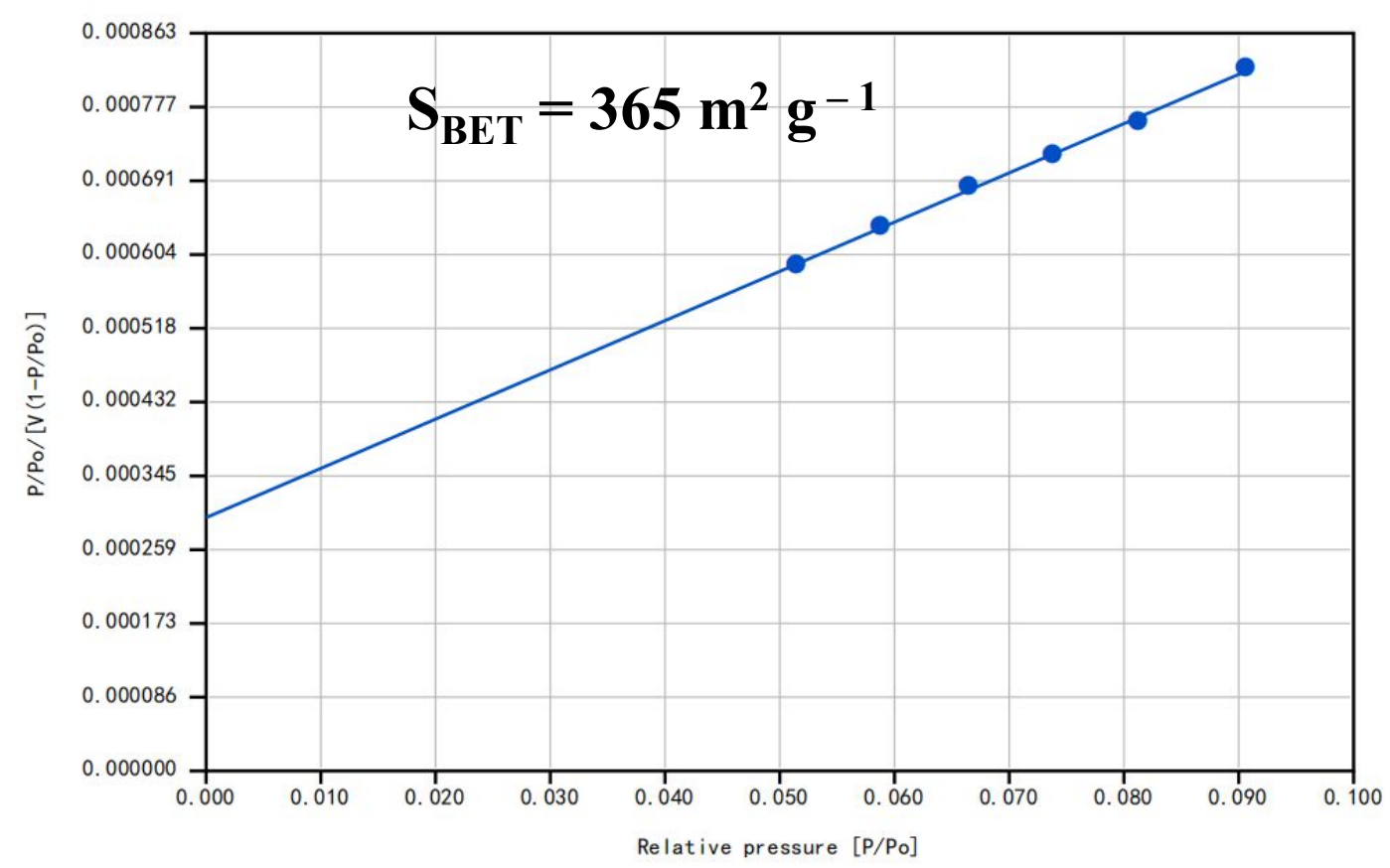

Figure S5. BET plot for XB-COF.

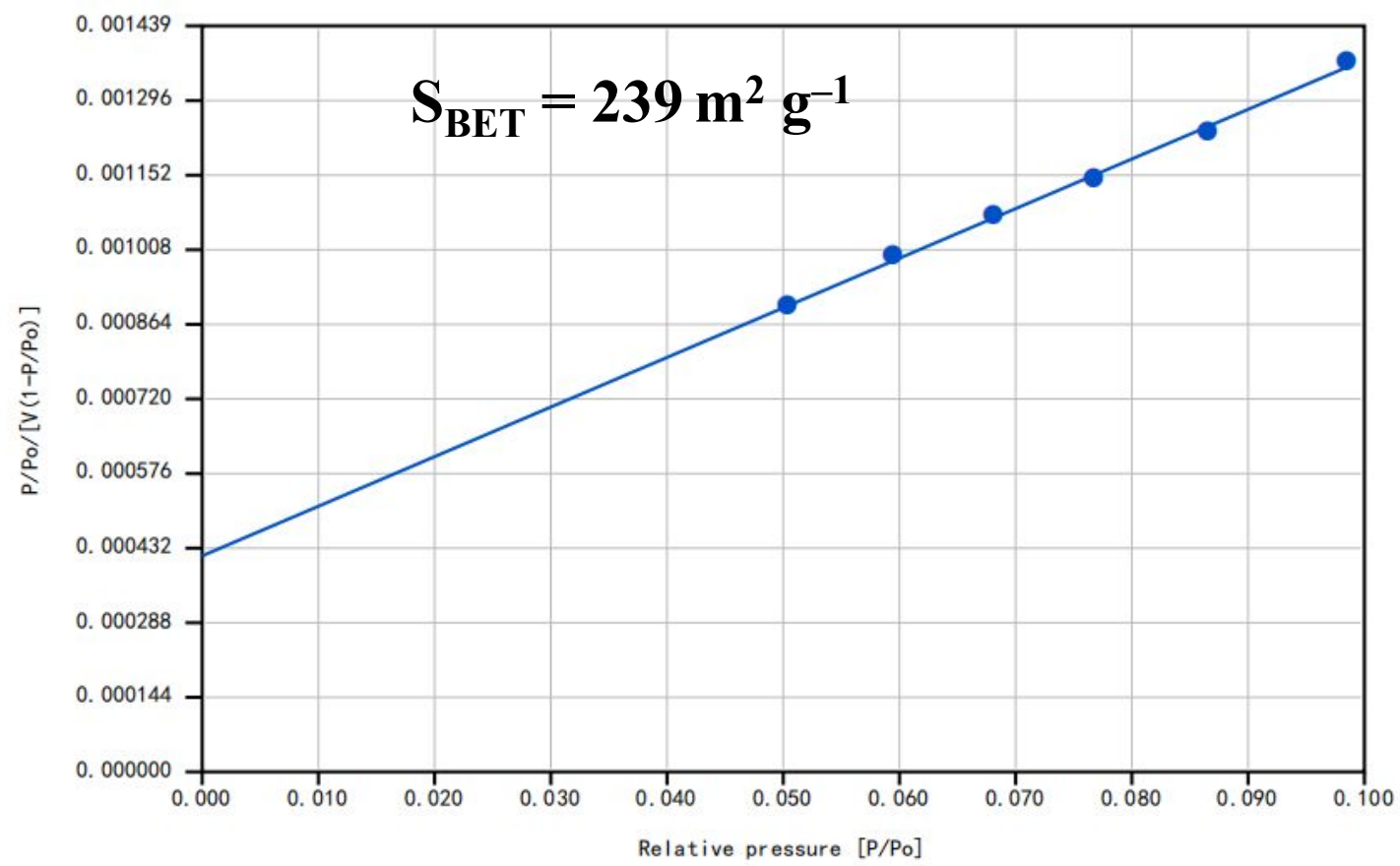

Figure S6. BET plot for XB-Pd-COF. 


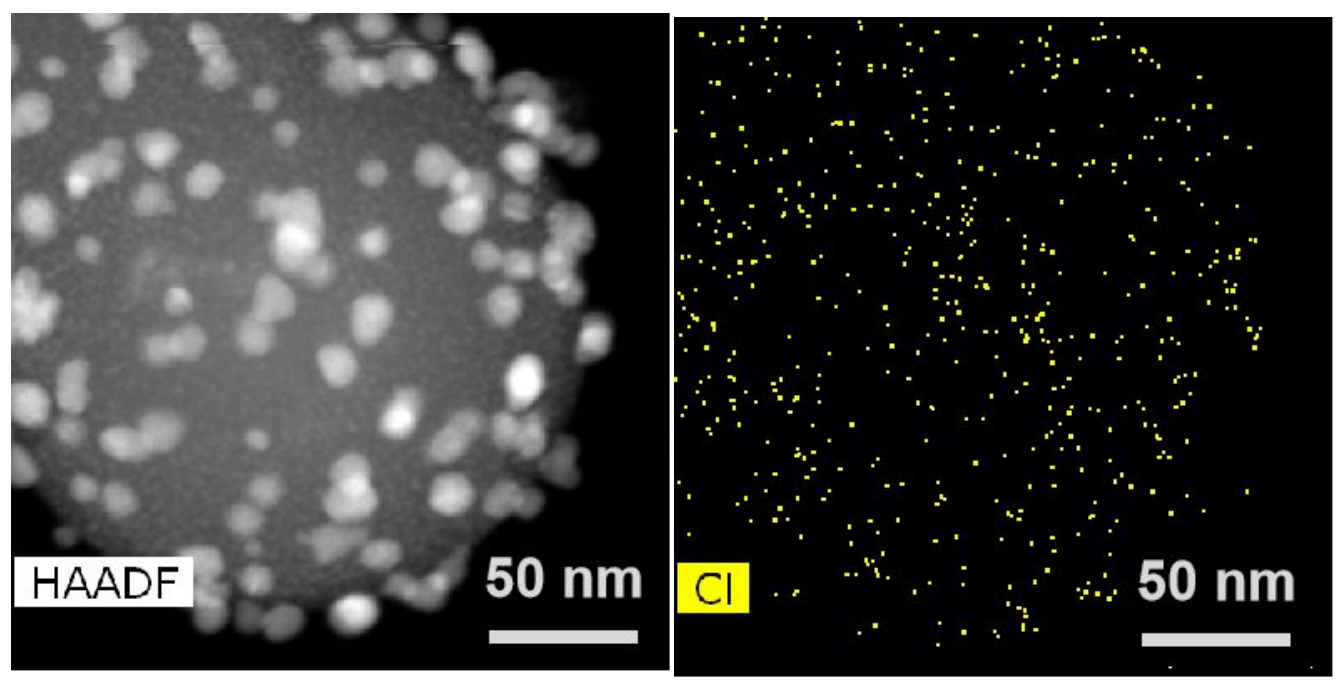

Figure S7. Elemental mapping images of XB-Pd-COF.

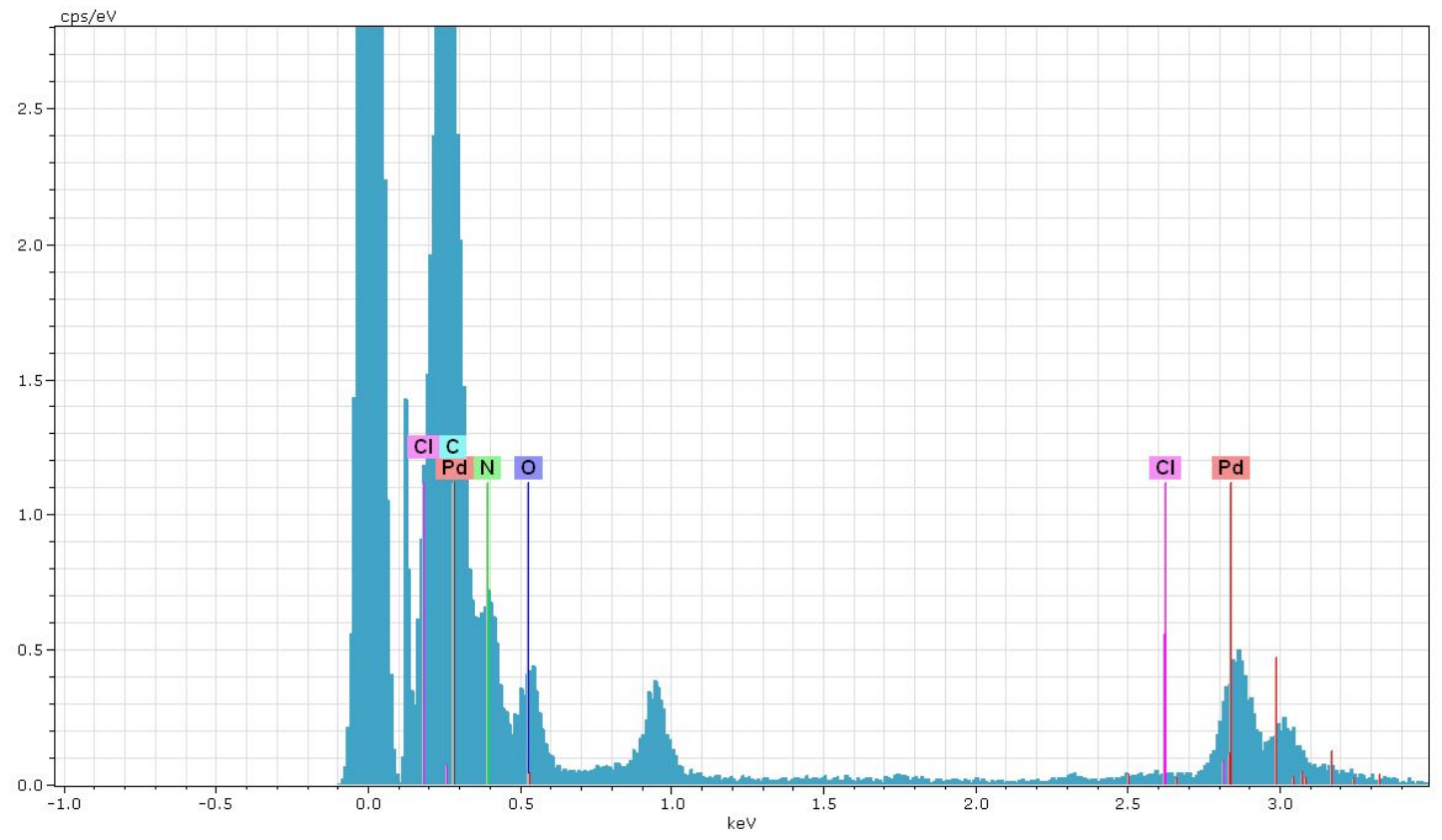

Figure S8. EDX spectra of XB-Pd-COF. 


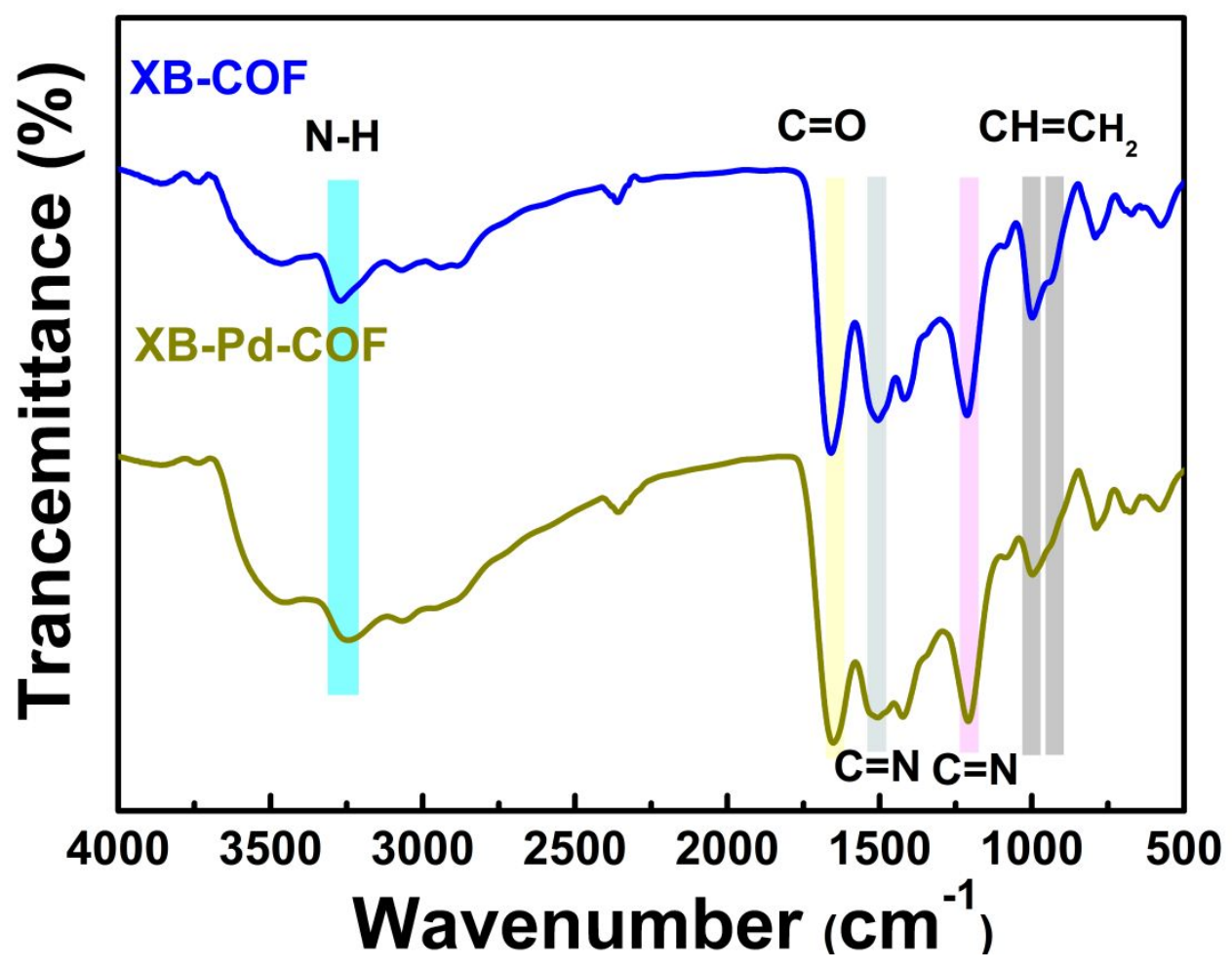

Figure S9. The FT-IR spectra of XB-COF and XB-Pd-COF.

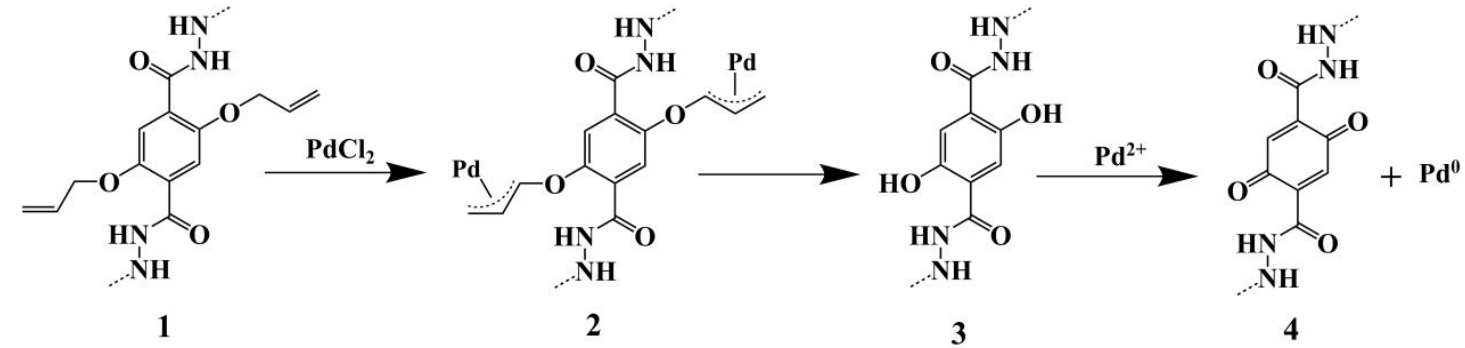

Figure S10. Formation mechanism of Pd NPs 


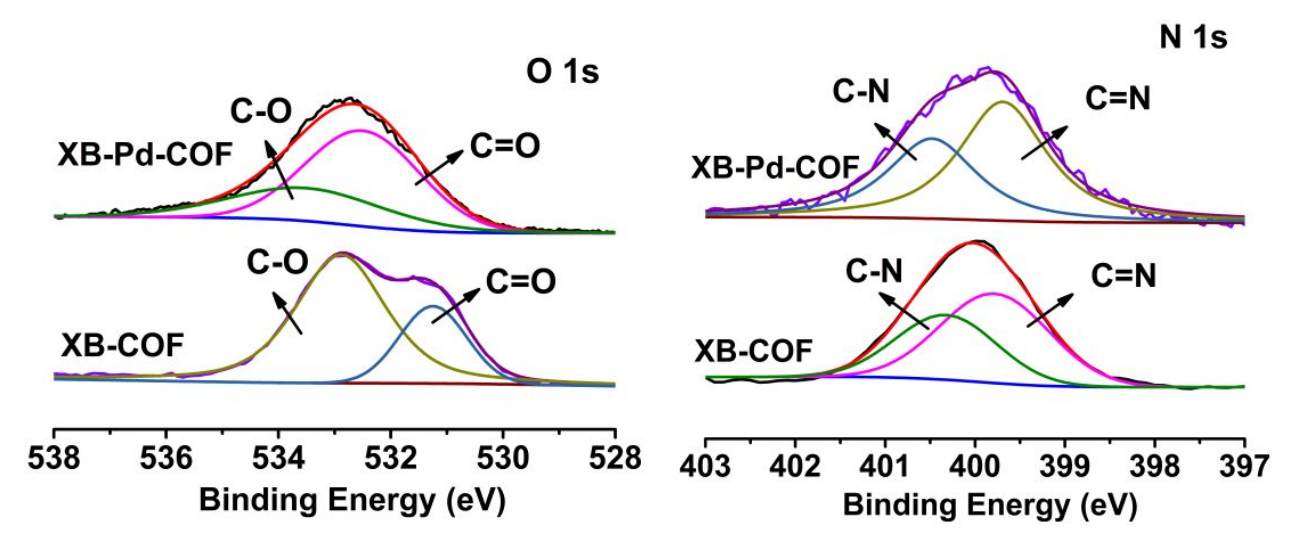

Figure S11. XPS survey spectra of XB-COF and XB-Pd-COF.

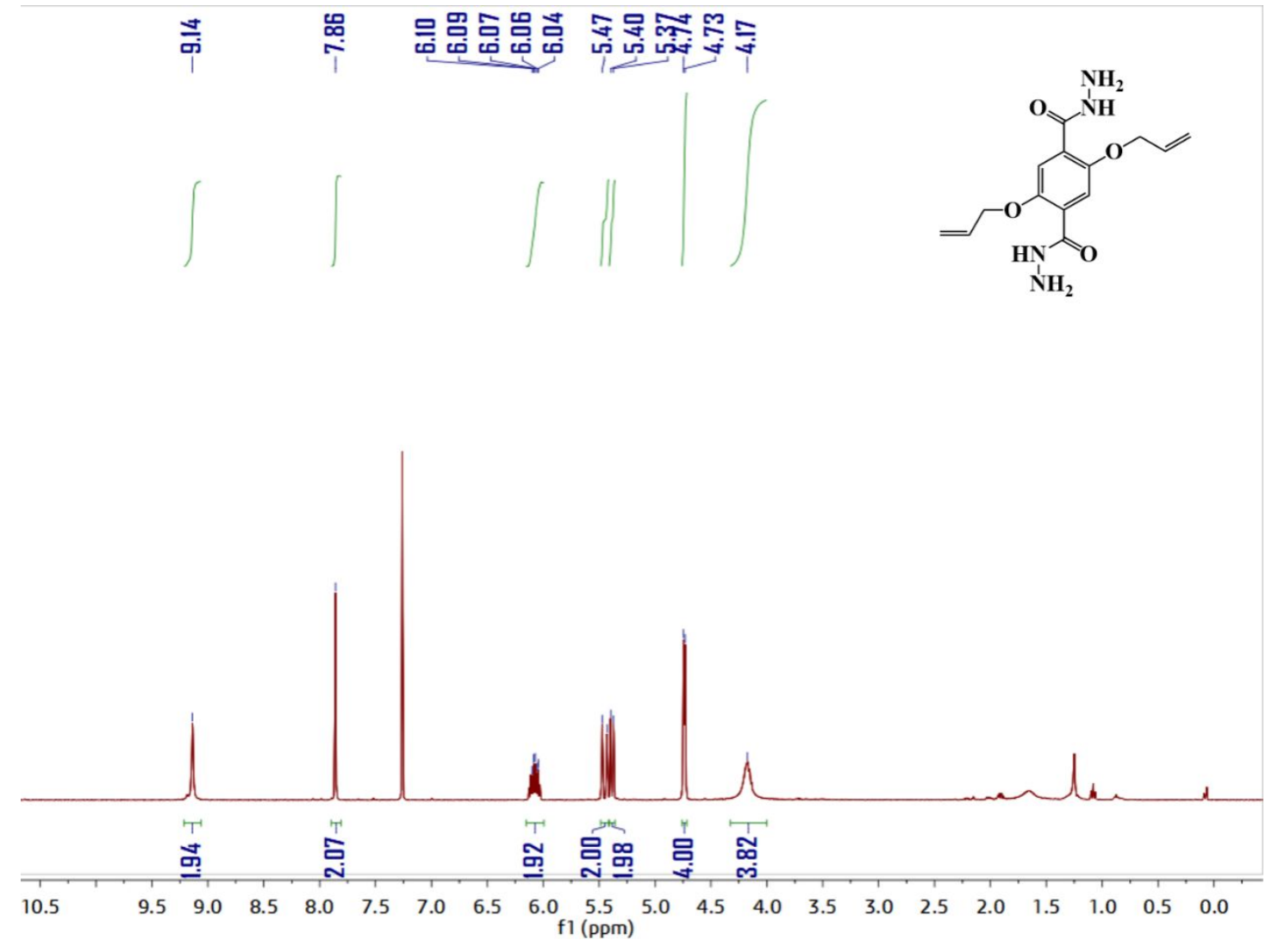

Figure S12. ${ }^{1} \mathrm{H}$ NMR spectrum of 2,5-Bis(allyloxy)terephthalohydrazide. 


\section{References}

(1) Uribe-Romo, F. J.; Doonan, C. J.; Furukawa, H.; Oisaki, K.; Yaghi, O. M. Crystalline Covalent Organic Frameworks with Hydrazone Linkages. J. Am. Chem. Soc. 2011, 133 (30), 11478-11481.

(2) Ding, S. Y.; Dong, M.; Wang, Y. W.; Chen, Y. T.; Wang, H. Z.; Su, C. Y.; Wang, W. Thioether-Based Fluorescent Covalent Organic Framework for Selective Detection and Facile Removal of Mercury (II). J. Am. Chem. Soc. 2016, $138(9), 3031-3037$.

(3) Li, X.; Gao, Q.; Wang, J.; Chen, Y.; Chen, Z. H.; Xu, H. Sen; Tang, W.; Leng, K.; Ning, G. H.; Wu, J.; Xu, Q. H.; Quek, S. Y.; Lu, Y.; Loh, K. P. Tuneable Near White-Emissive Two-Dimensional Covalent Organic Frameworks. Nat.

Commun. 2018, 9, 2325.

(4) Chen, G.; Lan, H. H.; Cai, S. L.; Sun, B.; Li, X. Le; He, Z. H.; Zheng, S. R.; Fan, J.; Liu, Y.; Zhang, W. G. Stable Hydrazone-Linked Covalent Organic Frameworks Containing O,N,O'-Chelating Sites for Fe(III) Detection in Water. ACS Appl. Mater. Interfaces 2019, 11 (13), 12830-12837.

(5) Liang, Y.; Feng, L.; Liu, X.; Zhao, Y.; Chen, Q.; Sui, Z.; Wang, N. Enhanced Selective Adsorption of NSAIDs by Covalent Organic Frameworks via Functional Group Tuning. Chem. Eng. J. 2021, 404 (August 2020), 127095. 